Article

\title{
Community Knowledge about Tuberculosis and Perception about Tuberculosis-Associated Stigma in Pakistan
}

\author{
Syed Mustafa Ali ${ }^{1, *(1)}$, Naveed Anjum ${ }^{1}$, Muhammad Ishaq ${ }^{1}$, Farah Naureen ${ }^{2}$, Arif Noor ${ }^{3}$, \\ Aamna Rashid ${ }^{4}$, Syed Muslim Abbas ${ }^{5}$ and Kerri Viney ${ }^{6}$ \\ 1 Monitoring, Evaluation and Learning Unit, Mercy Corps, Lane 9, Chak Shehzad, Park Road, \\ Islamabad 44000, Pakistan; naveedbaloch@hotmail.com (N.A.); muishaq@mercycorps.org (M.I.) \\ 2 Senior Director Programs, Mercy Corps, Lane 9, Chak Shehzad, Park Road, Islamabad 44000, Pakistan; \\ fnaureen@mercycorps.org \\ 3 Country Director, Mercy Corps, Lane 9, Chak Shehzad, Park Road, Islamabad 44000, Pakistan; \\ anoor@mercycorps.org \\ 4 Health Programs, Mercy Corps, Lane 9, Chak Shehzad, Park Road, Islamabad 44000, Pakistan; \\ aarashid@mercycorps.org \\ 5 Health Economics Unit, University of Birmingham, Birmingham B15 2TT, UK; taureanvibes@hotmail.com \\ 6 Department of Global Health, The Australian National University, Canberra, ACT 2600, Australia; \\ kerri.viney@anu.edu.au \\ * Correspondence: mustafa_30_84@yahoo.com
}

Received: 19 November 2018; Accepted: 18 January 2019; Published: 23 January 2019

\begin{abstract}
Tuberculosis- (TB) associated stigma is a well-documented phenomenon with various factors, both individual and societal, manifesting its role in shaping health-seeking behavior and contributing to suboptimal TB care in Pakistan. The objective of this study was to assess TB-related knowledge and perceived stigma among community members. This was a cross-sectional survey using a convenience sample of 183 individuals recruited between October and December 2017. A validated stigma measurement tool developed by Van Rie et al. was adapted. Data was analyzed using SPSS version 20.0. A clear majority was aware that TB is curable disease and that it is transmitted by coughing. However, respondents also thought that TB spread through contaminated food, sharing meals, sharing utensils, and by having sexual intercourse with a TB patient. In addition, females, unemployed, and persons having less than six years of education were also more likely to associate stigma with TB. We found an association between the lack of knowledge about TB and perceived stigma. This study highlights the need for improved TB-related education among communities.
\end{abstract}

Keywords: social stigma; tuberculosis; knowledge; stigma measurement; Pakistan

\section{Introduction}

Described as the world's leading infectious disease, tuberculosis (TB) continues to affect an estimated 10.4 million people worldwide annually. Pakistan is one of the 30 high burden TB countries globally that, combined, account for $56 \%$ of the global TB burden [1]. Lack of disease-specific knowledge may contribute to the high TB burden in Pakistan [2]. Prior knowledge about the disease is known to determine a person's response to the disease [3]. Prevailing misconceptions about TB lead to social discrimination [4], social aversion [5], and stigmatization. Additionally, TB knowledge and stigmatization are linked with healthcare-seeking behavior and subsequent healthcare seeking [6]. 
Stigmatization is a complex phenomenon that affects institutional, community level, and individual level attitudes. Its identification, characterization, and measurement over time make it a challenge with regard to the development of de-stigmatization-focused interventions $[7,8]$. The concept of stigma was first introduced by Goffman in 1963 and was described as a trait that lowers an individual from a usual person to a tainted one [9]. Stigma generates a sense of disvalue [10], and stigmatized individuals may internalize feelings of guilt, shame, and disgust [9]. This leads to development of a set of behaviors that put a stigmatized individual at risk, such as avoidance behavior, withdrawal from interpersonal relationships, self-isolation, and delayed health-seeking behavior [11,12]. In addition, it may result in psychological stress, depression, fear, and further deterioration of health [13-15].

Stigma is also a social determinant of health that is promulgated by community norms and is likely to influence inter- and intrapersonal attitudes [8]. Social inequalities may result in the negative labeling of particular characteristics, which suggests that stigma is socially constructed. In certain situations, differences in race, class, religion, and gender are used as a tool for further marginalization of the already stigmatized individuals, hence multiplying the effects of stigma $[7,10,16,17]$.

Globally, a number of studies have examined TB-associated stigma and its consequences have been documented in a number of settings [18]. Stigma negatively impacts public health efforts for early diagnosis and treatment [10]. For instance, stigma is a factor which contributes to delayed diagnosis [19] and treatment nonadherence [20].

TB-associated stigma is thought to be a major problem in Pakistan perpetuated by myths and misconceptions about the disease. In the context of Pakistan, there are some qualitative data available on TB-associated stigma $[6,21]$. However, none of the quantitative studies used validated stigma measurement scales to quantify it. Our work is influenced by the description of health-related stigma as a social process of characterizing personal experience or anticipation of negative social judgment of a person or group of individuals with a particular health problem, such as isolation, exclusion, rejection, and shame [22].

Therefore, we aimed to assess community knowledge about TB and perceptions of TB-associated stigma by interviewing a sample of people attending private healthcare clinics in Pakistan. The objectives of this study were twofold: (1) To assess TB-related knowledge, and (2) to assess perceived stigma associated with TB. Through these objectives, our study aims to address the following: Does knowledge about tuberculosis, along with demographic factors, have an association with TB-related stigma? The findings of this study will also inform the development of educational and awareness raising activities to reduce TB-related stigma.

\section{Materials and Methods}

\subsection{Study Setting}

Seventy-five districts participated in the Public Private Mix (PPM) model of the national TB control program in Pakistan. In the PPM model, there were approximately 2000 private healthcare providers who were involved in the implementation of PPM interventions and provided free TB treatment services. They were trained on Directly Observed Therapy (DOT) implementation and on the provision of standardized TB prevention and are services. A team of trained public health professionals visited them regularly and checked their compliance to treatment protocols.

\subsection{Study Design}

This was a cross-sectional survey using a convenience sample. 


\subsection{Sampling Approach}

A sample of 27 clinics was selected using convenience sampling from the 24 districts participating in the PPM model. Survey participants, over 18 years of age, regardless of sex and education, were then randomly selected from the outpatient department of these healthcare facilities as they visited the facility for consultation related to a general ailment. Every fourth person seated in the waiting area from the right-hand side of the entrance was approached for interview. If participation invitation was declined, then next fourth person was invited, and informed consent was sought. From each practice or clinic, six to eight respondents were recruited based on the availability of willing people seated in the waiting area.

\subsection{Data Collection}

The data collection tool was a stigma measurement scale [23] developed by Van Rie et al., with minor modifications for the linguistic and sociocultural context of Pakistan. The tool consisted of two subscales: (1) A subscale for measuring the community's perception about TB, and (2) a subscale for measuring the community's knowledge about TB. Demographic information was also collected.

Seventeen questions constituted the perception subscale, where each question contained four responses (i.e., strongly agree, agree, disagree, and strongly disagree). 'Strongly agree' and 'agree' represented the presence of perceived stigma and 'strongly disagree' and 'disagree' represented the absence of perceived stigma. The knowledge subscale included a range of questions concerning facts about TB causation and acquisition with closed responses of 'Yes, ' No,' or 'Don't Know.'

Face-to-face interviews were administered by trained interviewers at the PPM-enrolled primary healthcare clinic between October and December 2017. Interviews were conducted within the premises of the healthcare clinic, ensuring privacy and confidentiality. These interviews were carried out during routine monitoring visits of the public health professionals.

\subsection{Data Analysis}

Data were collected in ODK Collect and were exported to SPSS for analysis (Version 20.0).

The presence of stigma (i.e., a response of 'strongly agree' or 'agree') was assigned a score of 1 , whereas the absence of stigma (i.e., a response of 'strongly disagree' or 'disagree') was assigned 0. A total stigma score was calculated by adding the scores of all questions. A mean stigma score (i.e., 44) was calculated by using the total stigma score $(n=8142)$ as the numerator and the study population as denominator $(n=183)$. Stigma scores range from 1 to 4 , where the number corresponds to the degree of stigmatization, i.e., the higher the number, the higher the level of stigma. Respondents who had an individual total stigma score higher than the mean score were categorized as persons with high levels of stigma toward $\mathrm{TB}$, whereas respondents with an individual total stigma score less than the mean score were categorized as persons with low levels of stigma toward TB. Other variables, such as location, educational level, employment status, knowledge about TB (i.e., knowledge that TB is curable and TB spreads through coughing) were dichotomized for the analysis. We used descriptive analyse and calculated numbers, proportions, and odds ratios with $95 \%$ confidence intervals.

\subsection{Ethical Approval}

Ethical approval was provided by the Ethical Review Board of Health Oriented Preventive Education (HOPE), which is recognized by the United States Department of Health and Human Services Office for Human Research Protection (OHRP). Oral informed consent was obtained from each participant. 


\section{Results}

A total of 183 individuals ( $n=134,73 \%$ males; $n=49,27 \%$ females) participated in the study with a mean age of 37 years $( \pm 12)$ (Table 1$)$. Seventy-three percent $(n=134)$ were aged $25-54$ years and $69 \%(n=127)$ resided in urban areas (Table 1$)$. Fifty-one percent of the respondents $(51 \% ; n=93)$ were recruited from the province of Punjab (Table 1). The majority were Muslim $(91 \% ; n=167)$ and 32\% $(n=58)$ had 13-16 years of education (Table 1$)$. Twenty-eight percent $(n=52)$ of respondents were illiterate. In terms of occupation, $26 \%$ of respondents $(n=48)$ were not employed (i.e., unemployed, housewife, student), 30\% $(n=55)$ were labourers, $19 \%(n=35)$ were involved in a business and the remaining $25 \%(n=45)$ were either government employees or in the private sector (see Table 1$)$.

Table 1. Sociodemographic characteristics of study participants.

\begin{tabular}{|c|c|c|}
\hline Characteristics & Variables & Number (Percentage) \\
\hline \multirow{2}{*}{ Sex } & Male & $134(73)$ \\
\hline & Female & $49(27)$ \\
\hline \multirow{5}{*}{ Age (years) } & Early working age (15-24) & $31(17)$ \\
\hline & Prime working age (25-35) & $66(36)$ \\
\hline & Prime working age (36-54) & $68(37)$ \\
\hline & Mature working age (55-64) & $13(7)$ \\
\hline & Elderly $(\geq 65)$ & $5(3)$ \\
\hline Mean Age (SD) & & $37( \pm 12)$ \\
\hline \multirow{5}{*}{ Years of Education } & Illiterate & $52(28)$ \\
\hline & Till primary (1-5) & $32(18)$ \\
\hline & 6-8 & $27(15)$ \\
\hline & $9-12$ & $14(8)$ \\
\hline & $13-16$ & $58(32)$ \\
\hline \multirow{8}{*}{ Occupation } & Unemployed & $4(2)$ \\
\hline & Housewife & $28(15)$ \\
\hline & Student & $16(9)$ \\
\hline & Laborer & $55(30)$ \\
\hline & Small scale business owner & $17(9)$ \\
\hline & Business (or landlord) & $18(10)$ \\
\hline & Government employee & $3(2)$ \\
\hline & Private sector employee & $42(23)$ \\
\hline \multirow{3}{*}{ Religion } & Muslim & $167(91)$ \\
\hline & Christian & $1(0.5)$ \\
\hline & Hindu & $15(8.5)$ \\
\hline \multirow{2}{*}{ Location } & Urban & $127(69)$ \\
\hline & Rural & $56(31)$ \\
\hline \multirow{4}{*}{ Province } & Punjab & $93(51)$ \\
\hline & Sindh & $57(31)$ \\
\hline & Khyber Pakhtunkhwa & $12(7)$ \\
\hline & Balochistan & $21(11)$ \\
\hline \multicolumn{2}{|c|}{ Total } & 183 \\
\hline
\end{tabular}

\section{Community Perceptions about Tuberculosis}

Seventy-four percent of respondents $(n=136)$ stated that people would feel uncomfortable if they were close to a person with TB and $38 \%(n=78)$ of respondents commented that people would think that a person with TB is disgusting (Table 2$)$. Sixty-two percent of respondents $(n=113)$ expressed their fear of someone with TB, however, approximately half of the respondents $(52 \% ; n=95)$ said that some people try not to touch others with TB (Table 2). Twenty-seven percent of respondents (27\%; $n=49$ ) said that people would not prefer a person with TB living in the same community (Table 2). Figure 1 exhibits perceived behaviors of community members for a person with TB. 
Table 2. Level of perceived stigma associated with tuberculosis.

\begin{tabular}{lcc}
\hline & \multicolumn{2}{c}{ Status of Stigma for Each Item } \\
\cline { 2 - 3 } & Present (\%) & Absent (\%) \\
\hline Some people may not like to eat and drink with relatives who have TB & $143(78)$ & $40(22)$ \\
Some people feel uncomfortable about being near those with TB & $136(74)$ & $47(26)$ \\
If a person has TB, some community members will behave differently towards & $81(44)$ & $102(56)$ \\
that person for the rest of his/her life, even if s/he is treated and cured & $118(64)$ & $65(36)$ \\
Some people do not want those with TB playing with their children & $136(74)$ & $47(26)$ \\
Some people keep their distance from people with TB & $70(38)$ & $113(62)$ \\
Some people think that those with TB are disgusting & $63(34)$ & $120(66)$ \\
Some people do not want to talk to others with TB & $113(62)$ & $70(38)$ \\
Some people are afraid of those with TB & $95(52)$ & $88(48)$ \\
Some people try not to touch others with TB & $139(76)$ & $44(24)$ \\
Some people may not like to eat and drink with friends who have TB & $49(27)$ & $134(73)$ \\
Some people prefer not to have those with TB living in their community & $131(72)$ & $52(28)$ \\
Some people think that those with TB, both male and female face same social & & $41(22)$ \\
problems (marriage, job, continuing education, attending social gatherings etc.) & $142(78)$ & $26(14)$ \\
Some people think that those males with TB face more problems in marriage & $157(86)$ & $78(43)$ \\
Some people think that those females with TB face more problems in marriage & $105(57)$ & $108(59)$ \\
Some people think that those females with TB depend economically on their & & $145(79)$ \\
husbands and in-laws and need their cooperation to obtain treatment & $75(41)$ & $38(21)$ \\
Some people think that a family with TB patient should not allowed to & & \\
participate in any social function & & \\
Some people think that female TB patient should be sent off to her parent's house & &
\end{tabular}

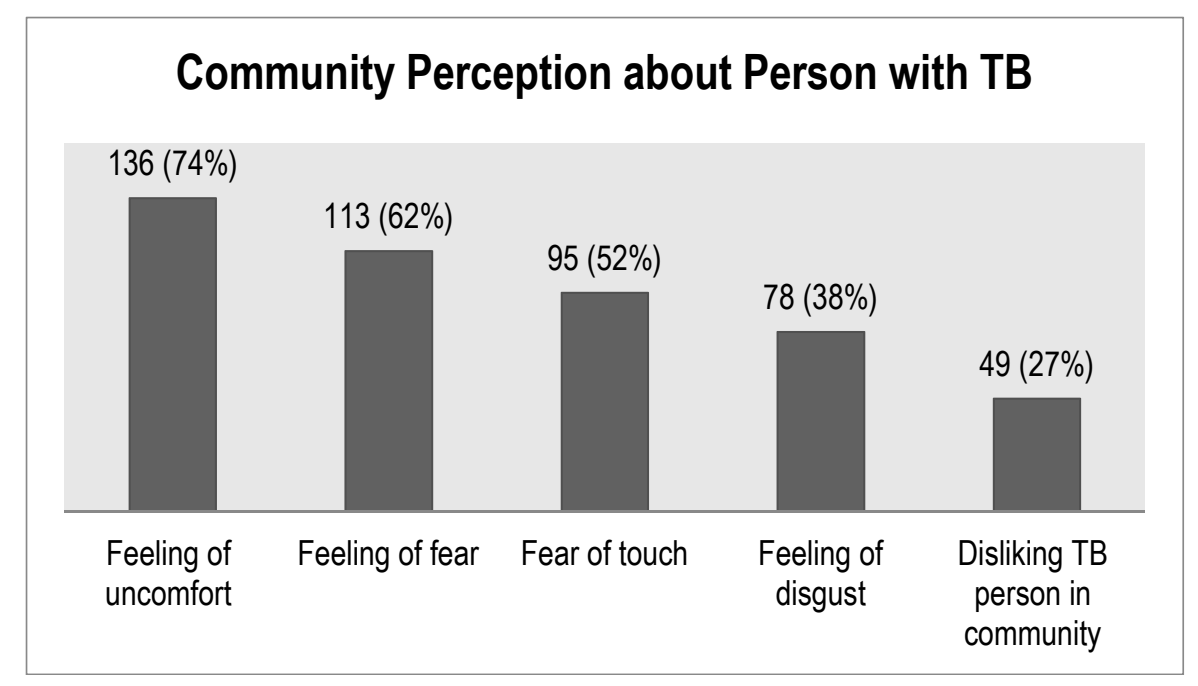

Figure 1. Community perception about person with tuberculosis.

\section{Social Isolation}

The respondents stated that people with TB may not like to eat and drink with relatives $(78 \%$; $n=143)$ and friends $(76 \% ; n=139)$, and $74 \%(n=136)$ said that people keep their distance from a person with TB (Table 2$)$. However, relatively fewer respondents $(34 \% ; n=63)$ said that some people do not want to talk to a person with TB (Table 2). Approximately half of the respondents $(52 \% ; n=95)$ commented that some people do not try to touch others with TB and $41 \%(n=75)$ said that some people think that a family with TB patient should not be allowed to participate in any social gathering (Table 2). Forty-four percent of the respondents $(n=81)$ said that community members will behave differently toward persons with TB for the rest of their lives, even if they have been treated (Table 2). Figure 2 displays key perceptions of community members about social activities of a person with TB. 


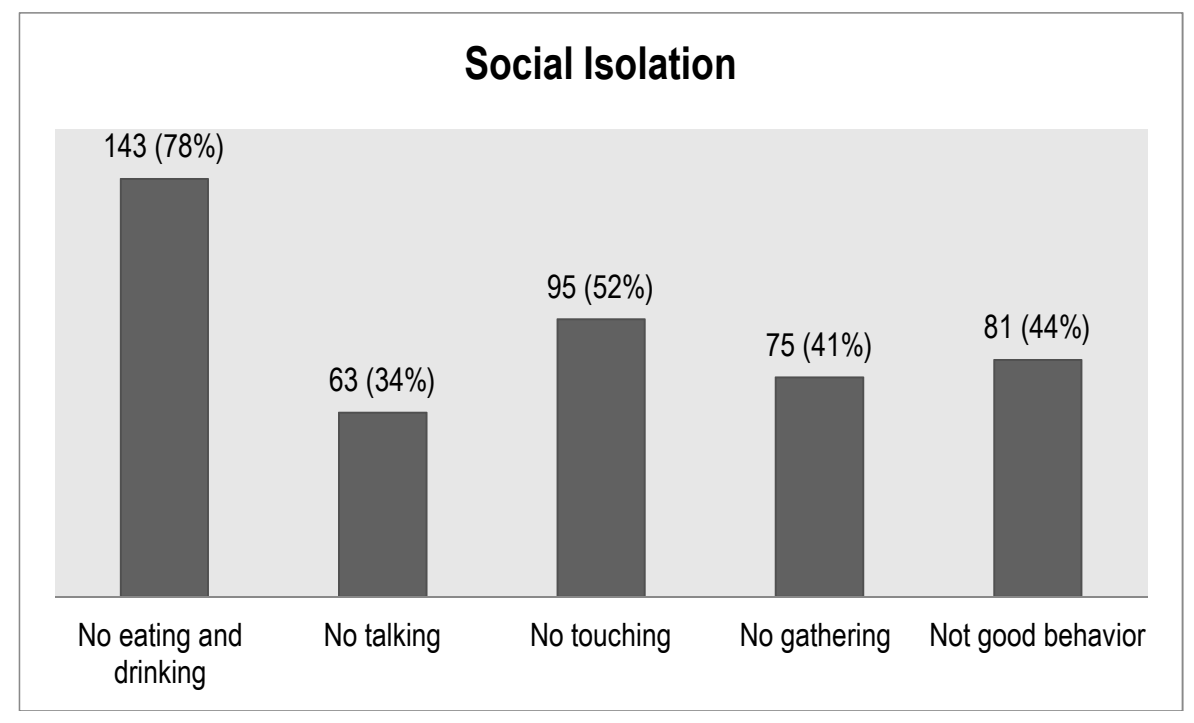

Figure 2. Community perception about isolating a person with TB.

\section{Gender Perspectives Regarding Tuberculosis}

Seventy-two percent of respondents $(n=131)$ thought that a person with TB faces social challenges, such as diminished marriage prospects, discontinuation of employment and education, and disallowed participation in social gatherings. Specifically, $78 \%$ of the respondents thought that a male with TB may face problems in finding a wife, however, relatively a higher proportion $(86 \% ; n=157)$ of respondents stated that a female with TB faced diminished marriage prospects. More than half of the respondents $(57 \% ; n=105)$ thought that females with TB are dependent upon the support of their husbands and their husbands' parents to receive treatment. Approximately one-fifth of respondents $(21 \% ; n=38)$ said that some people think that a female with TB should be sent back to her parent's home from her husbands' family home (Table 2).

\section{Knowledge about Tuberculosis}

A clear majority of community members were aware that TB is curable disease $(87 \% ; n=159)$ and that it spreads by coughing $(91 \% ; n=167)$. However, community members also stated that it was transmitted through contaminated food $(73 \% ; n=134)$, sharing meals $(55 \% ; n=100)$, unclean water and food $(62 \% ; n=114)$, sharing eating utensils $(53 \% ; n=96)$, touching $(33 \% ; n=61)$, and by having sex with a person with TB $(51 \% ; n=93)$ (Figure 3). Half of the respondents $(50 \% ; n=91)$ said that emotional stress is a cause of TB and $30 \%$ of the respondents $(n=54)$ thought that TB leads to infertility (Table 3).

Table 3. Knowledge about TB among community members.

\begin{tabular}{cc}
\hline Knowledge Variable & Number (\%) \\
\hline TB is curable & $159(87)$ \\
TB patient also has HIV / AIDS & $45(25)$ \\
TB leads to infertility & $54(30)$ \\
Emotional stress is a cause of TB & $91(50)$ \\
\hline \multicolumn{2}{c}{ Perceived mode of TB transmission } \\
\hline Contaminated food & $134(73)$ \\
Cough & $167(91)$ \\
Sharing meal with a person with TB & $100(55)$ \\
Unclean water and food & $114(62)$ \\
Sharing utensils with a person with TB & $96(53)$ \\
Touching a person with TB & $61(33)$ \\
Sex with a person with TB & $93(51)$ \\
\hline
\end{tabular}




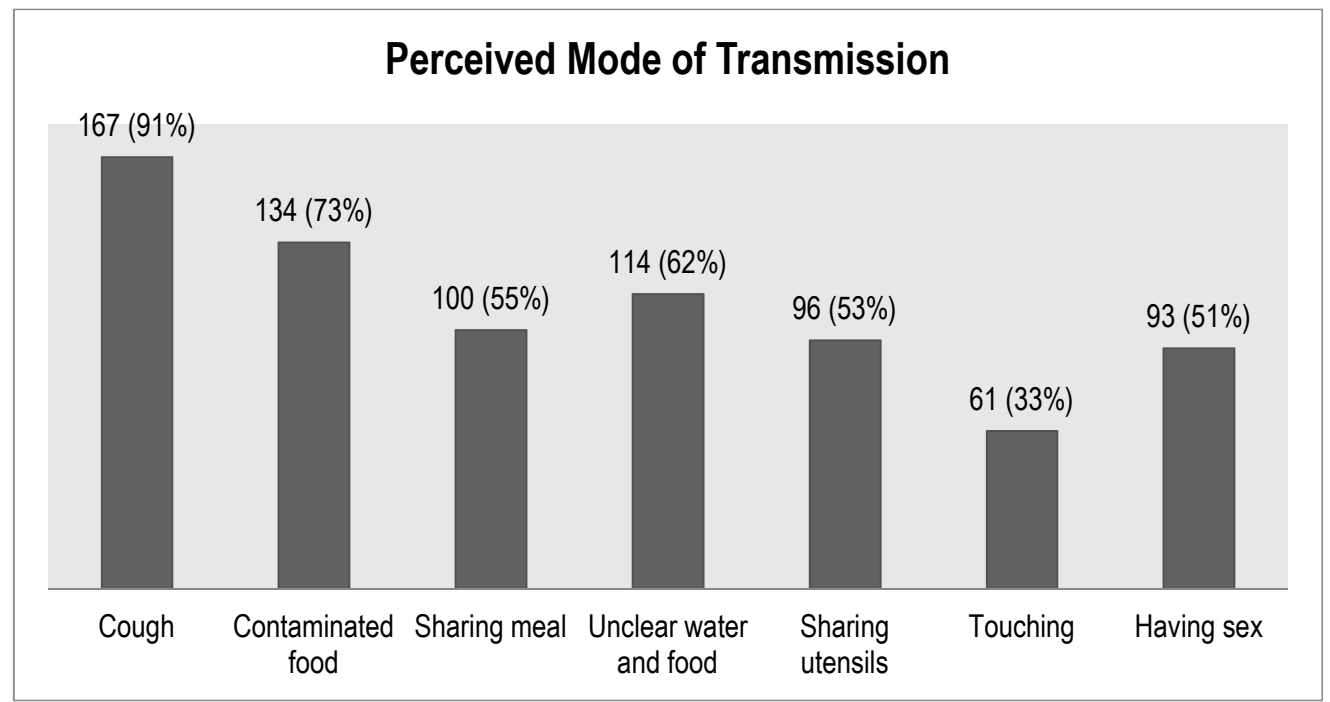

Figure 3. Community perception about probable mode of tuberculosis (TB) transmission.

\section{Factors Associated with Stigma}

More than half of the respondents $(57 \% ; n=104)$ associated TB with high levels of stigma (Table 4$)$. Individuals with education less than sixth grade were more likely to associate stigma with TB than those with higher levels of education (crude OR $=1.2 ; 95 \%$ CI: 0.89, 1.72) (Table 4). Respondents who lacked knowledge that TB is curable were also more likely to associate TB with stigma (crude $\mathrm{OR}=3.42 ; 95 \% \mathrm{CI}: 1.20,9.70$ ). Similarly, those who lacked knowledge that TB is spread by coughing were also more likely to associate stigma with TB (crude OR $=1.27 ; 95 \%$ CI: $0.49,3.34$ ) (Table 4).

Table 4. Factors associated with perceived stigma about tuberculosis.

\begin{tabular}{ccccc}
\hline \multirow{2}{*}{ Variable } & & \multicolumn{2}{c}{ Stigma Level } & \multirow{2}{*}{$\begin{array}{c}\text { Crude Odds Ratio } \\
\mathbf{( 9 5 \%} \text { CI) }\end{array}$} \\
\cline { 2 - 4 } & & High $\boldsymbol{n} \mathbf{( \% )}$ & Low $\boldsymbol{n} \mathbf{( \% )}$ & $0.82(0.63,1.06)$ \\
Sex & Male & $72(53.7)$ & $62(46.3)$ & $1.33(0.87,2.04)$ \\
\hline \multirow{2}{*}{ Urban or Rural } & Female & $32(65.3)$ & $17(34.7)$ & $0.99(0.82,1.21)$ \\
Location & Urban & $72(56.7)$ & $55(43.3)$ & $1.01(0.65,1.57)$ \\
\hline \multirow{2}{*}{ Education Level } & Rural & $32(57.1)$ & $24(42.9)$ & $1.2(0.89,1.72)$ \\
& Till grade 5 & $52(61.9)$ & $32(38.1)$ & $0.84(0.64,1.10)$ \\
\hline \multirow{2}{*}{ Employment Status } & Above grade 5 & $52(52.5)$ & $47(47.5)$ & $0.98(0.82,1.17)$ \\
& Employed & $76(56.3)$ & $59(43.7)$ & $1.06(0.65,1.74)$ \\
\hline \multirow{2}{*}{ TB is curable } & Unemployed & $28(58.3)$ & $20(41.7)$ & $0.87(0.79,0.96)$ \\
& Yes & $86(53.4)$ & $75(46.6)$ & $3.42(1.20,9.70)$ \\
\hline \multirow{2}{*}{ TB spreads through } & No & $18(81.8)$ & $4(18.2)$ & $0.98(0.89,1.07)$ \\
cough & Yes & $94(56.3)$ & $73(37.5)$ & $1.27(0.49,3.34)$ \\
\hline
\end{tabular}

\section{Discussion}

Stigma associated with health conditions, such as HIV / AIDS, leprosy, TB, mental illness, and epilepsy, is a global and social phenomenon that affects individuals suffering from disease and their families. As a result, the effectiveness of public health programs in preventing disease progression, as well as diagnosing and treating these conditions, may also be affected [24]. Accordingly, organizational and community norms that result in the stigmatization of $\mathrm{TB}$ are believed to damage efforts to prevent, diagnose, and treat TB [20]. In our study, TB was perceived as a stigmatized health condition by 
community members from outpatient clinics. However, the level of stigma varied by sex, educational level, employment status, and the degree of disease-specific knowledge.

In our study, the majority of the community was aware that TB spreads through coughing (91\%) and it is curable (87\%). These are similar findings to those of other studies. For example, in Brazil, $91 \%$ of individuals believed that TB spreads through coughing [25] and in Somalia, this figure was lower, at 59\% [26]. However, although many respondents understood the correct mode of TB transmission, a sizeable proportion of respondents had incorrect knowledge about TB transmission. For example, half of the respondents considered stress as cause of TB, and a similar finding was also reported in Karachi, Pakistan (57\%) [27] and in Vanuatu (17\%) [28]. Similarly, in our study, 53\% considered sharing utensils as a potential mode of TB transmission, a common finding in other studies: $57 \%$ in Karachi, Pakistan [27] and 36\% in Somalia [26].

Existing literature highlights the significance of community-based awareness strategies to eliminate misconceptions and wrong beliefs about TB [29,30]. However, studies are scarce, and few studies focus on interventions among community members. In a recent systematic review, which focused on evidence-based interventions to reduce TB related stigma, only two of seven interventions were aimed at reducing TB-related stigma in the community [31]. In one of these studies, conducted in Nigeria, 10 community volunteers were trained to provide TB education to the community and to detect and refer persons with presumptive TB to a nearby clinic [32]. Based on surveys conducted pre- and post-intervention, mean knowledge scores increased significantly and mean attitude scores (including stigmatizing attitudes) decreased significantly after the intervention, indicating a positive effect of community education [33]. In the other study on a community-based stigma reduction intervention, knowledge and attitude surveys were conducted in different areas of Bangladesh, some of which had received community-based educational interventions about TB and leprosy [33]. In the areas that had received the educational intervention, there were better levels of knowledge about TB symptoms ( $90 \%$ thought that cough was a symptom in the areas that received the educational intervention vs. $44 \%$ in the nonintervention areas) [33]. Moreover, in the nonintervention areas, $76 \%$ of respondents said that they would not buy goods from a shopkeeper with $\mathrm{TB}$, whereas in the intervention areas, this figure was reversed [33]. In addition, there are a number of other studies which focus on interventions to reduce stigma aimed at TB patients.

Demissie et al. (2003) reported that 'TB Clubs' were helpful in eliminating stigmatizing attitudes and enhancing patient's compliance to treatment through the exchange of patient support and information [34]. During the gatherings of $T B C l u b$ members and general communities, dissemination of education material was influential in changing people's attitudes towards TB. In addition to these TB specific interventions, broader rights-based approaches may also reduce TB related stigma. Smith (2002) has emphasized a broader rights-based approach to TB care with an aim to shift focus from disease-specific knowledge to enforcement of rights, such as access to care and prevention services, and confidentiality of patient's information, which will reduce stigma, discrimination, and inequalities in health [35].

Our study focused on the examination of perceived stigma, which should be given serious consideration because it reflects the prevalence of stigmatized beliefs and attitude of the community [36]. We found that unemployment, being female, living in a rural location, and incorrect knowledge about TB causation and transmission were associated with TB-related stigma, although only the belief that TB was not curable was statistically significant. Another study conducted in China among TB patients also noted a statistically significant association between less TB knowledge and TB-related stigma [37].

Individuals with different social, cultural, religious, and geographical background enjoy different levels of health. Due to these differences, coupled with different health perspectives, inequalities in health are observed [38]. Differences in gender promote vulnerability that leads to different consequences corresponding to different gender [39,40]. As we found, stigma associated with TB resulted in diminished marriage prospects of females than males in the south Indian urban 
community [41]. In addition, as a result of stereotypical gender roles in the community, female's health is graded as inferior because of male's predominant role in household economy [42]. Magnitude of stigma's effect on different gender is different, but it is acknowledged that both males and females, affected with TB, face psychological burdens with regard to their social responsibilities [43].

The cultural and social practices construct a sociocultural sphere of human activity that is highly relevant for TB including community norms about TB and perceptions of stigmatization [44]. Effective control of TB is associated with social determinants and social systems that require an interdisciplinary response beyond the purely biomedical model of disease causation, incorporating important social knowledge and concepts such as stigma [44,45]. TB-related stigma is acknowledged to shape poor health-seeking behavior and negatively impact health outcomes [46]. Therefore, social scientists emphasize the need for examination of unequal power distribution in social and economic contexts that positions individuals in this world differently, hence increasing their vulnerability [47]. In addition, characteristics of the healthcare system and the conditions in which people born, live, work, and grow (known as social determinants) influence the health status of individual and community at large $[48,49]$. Consequently, intersectionality has emerged as a conceptual framework to unfold these complexities with an aim to reduce difference or inequalities [50]. Intersectional approaches examine the hierarchies of race, class, gender, and other social identities to unlock the complexities that lie in a social phenomenon and its effect on individual's health or health outcome [50].

The main strength of this study is stigma measurement by means of a validated tool. Hence, this study can be considered inaugural in the context of TB control programs of Pakistan. Strict measures for ethics (e.g., privacy, confidentiality, and noncoercive participation) were taken to warrant trust in the findings of this study. There is general hesitation in discussing TB-like stigmatized conditions, which can be reduced through better study design. Therefore, our study can stimulate the design of large-scale studies. Our study has a few limitations, which should be considered carefully before utilizing the findings. Due to convenience sampling method, predominant representation of males in study population, and small sample size findings, this study cannot be theoretically generalized. However, we believe that even more robust scientific methodology and significant sample size are likely to generate, more or less, the same results.

\section{Conclusions}

Pakistan is a high-incidence TB country, and TB is a stigmatized disease with many misconceptions about how it is caused. TB-associated stigma remains despite decades of TB control efforts at the national level to correct misconceptions about the disease. Stigma was significantly associated with lack of knowledge about TB. However, it is acknowledged it is often difficult to design, implement, and evaluate interventions that aim to destigmatize TB, and also there is limited evidence on their effectiveness. For the effectiveness of education interventions, local culture should be thoroughly and carefully examined. At the same time, additional research on the stigma measurement and on the effectiveness of educational interventions to reduce TB-related stigma is needed. Our study also highlights that stigma and its intersection with society should be further examined if the issue is to be addressed comprehensively.

Author Contributions: S.M.A. conceived research idea and developed its methodology and N.A., F.N., A.R. contributed in its refinement. S.M.A., M.I., A.R. supervised the data collection and checked data for quality. S.M.A., N.A., S.M.A., K.V. planned and conducted data analysis. S.M.A. drafted paper and K.V. contributed significantly to the discussion section. N.A., F.N., A.N., K.V. reviewed draft several times and suggested changes. K.V. proofread the final version. All researcher read the final version of the draft before submission.

Funding: This research received no external funding.

Conflicts of Interest: The authors declare no conflict of interest.

Data Availability: The survey data used to support the findings of this study are available from the corresponding author upon request. 


\section{References}

1. World Health Organization. Global Tuberculosis Report 2017; WHO: Geneva, Switzerland, 2017.

2. Ali, S.S.; Rabbani, F.; Siddiqui, U.N.; Zaidi, A.H.; Sophie, A.; Virani, S.J.; Younus, N.A. Tuberculosis: Do we know enough? A study of patients and their families in an outpatient hospital setting in Karachi, Pakistan. Int. J. Tuberc. Lung Dis. 2003, 7, 1052-1058. [PubMed]

3. Williams, G.; Alarcon, E.; Jittimanee, S.; Walusimbi, M.; Sebak, M.; Berga, E.; Villa, T.S. Best Practice for the Care of Patients with Tuberculosis; A Guide for Low Income Countries; International Union against Tuberculosis and Lung Disease: Paris, France, 2007.

4. Baral, S.C.; Karki, D.K.; Newell, J.N. Causes of stigma and discrimination associated with tuberculosis in Nepal: A qualitative study. BMC Public Health 2007, 2, 211. [CrossRef] [PubMed]

5. Khan, A.; Walley, J.; Newell, J.; Imdad, N. Tuberculosis in Pakistan: Socio-cultural constraints and opportunities in treatment. Soc. Sci. Med. 2000, 50, 247-254. [CrossRef]

6. Hoa, N.P.; Thorson, A.E.; Long, N.H.; Diwan, V.K. Knowledge of tuberculosis and associated health-seeking behavior among rural Vietnamese adults with a cough for at least three weeks. Scand. J. Public Health 2003, 62, 59-65.

7. Parker, R.; Aggleton, P. HIV and AIDS-related stigma and discrimination: A conceptual framework and implications for action. Soc. Sci. Med. 2003, 57, 13-24. [CrossRef]

8. Heijnders, M.; Van Der Meij, S. The fight against stigma: An overview of stigma reduction strategies and interventions. Psychol. Health Med. 2006, 11, 353-363. [CrossRef] [PubMed]

9. Goffman, E. Stigma: Notes on the Management of Spoiled Identity; Simon \& Schuster: New York, NY, USA, 1963.

10. Link, B.; Phelan, J. Conceptualizing stigma. Annu. Rev. Sociol. 2001, 27, 363-385. [CrossRef]

11. Smith, R.; Rossetto, K.; Peterson, B.L. A meta-analysis of disclosure of one's HIV-positive status, stigma and social support. AIDS Care 2008, 20, 1266-1275. [CrossRef] [PubMed]

12. Collins, P.Y.; Von-Unger, H.; Armbrister, A. Church ladies, good girls, and locas: Stigma and the intersection of gender, ethnicity, mental illness and sexuality in relation to HIV risk. Soc. Sci. Med. 2008, 67, 389-397. [CrossRef] [PubMed]

13. Woith, W.M.; Rappleyea, M.L. Emotional representation of tuberculosis with stigma, treatment delay, and medication adherence in Russia. J. Health Psychol. 2016, 21, 770-780. [CrossRef] [PubMed]

14. Nicholls, P.G.; Wiens, C.; Smith, W.C. Delay in presentation in the context of local knowledge and attitude towards leprosy-The results of qualitative fieldwork in Paraguay. Int. J. Leprosy Other Mycobact. Dis. 2003, 71, 198-209. [CrossRef]

15. Piot, P.; Coll Seck, A.M. International response to the HIV/AIDS epidemic: Planning for success. Bull. World Health Organ. 2001, 79, 1106-1112. [PubMed]

16. Frost, D.M. Social stigma and its consequences for the socially stigmatized. Soc. Personal. Psychol. Compass. 2011, 5, 824-839. [CrossRef]

17. Mill, J.E.; Edwards, N.; Jackson, R.C.; MacLean, L.; Chaw-Kant, J. Stigmatization as a social control mechanism for persons living with HIV and AIDS. Qual Health Res. 2010, 20, 1469-1483. [CrossRef] [PubMed]

18. Courtwright, A.; Turner, A.N. Tuberculosis and stigmatization: Pathways and interventions. Public Health Rep. 2010, 125 (Suppl. 4), 34-42. [CrossRef] [PubMed]

19. Li, Y.; Ehiri, J.; Tang, S.; Li, D.; Bian, Y.; Lin, H.; Marshall, C.; Cao, J. Factors associated with patient, and diagnostic delays in Chinese TB patients: A systematic review and meta-analysis. BMC Med. 2013, 11, 156. [CrossRef] [PubMed]

20. Xu, W.; Lu, W.; Zhou, Y.; Zhu, L.; Shen, H.; Wang, J. Adherence to anti-tuberculosis treatment among pulmonary tuberculosis patients: A qualitative and quantitative study. BMC Health Serv. Res. 2009, 9, 169. [CrossRef]

21. Liefooghe, R.; Michiels, N.; Habib, S.; Moran, M.B.; De Muynck, A. Perception and social consequences of tuberculosis: A focus group study of tuberculosis patients in Sialkot, Pakistan. Soc. Sci. Med. 1995, 41, 1685-1692. [CrossRef]

22. Weiss, M.G.; Ramakrishna, J. Stigma interventions and research for international health. Lancet 2006, 367, 536-538. [CrossRef] 
23. Van Rie, A.; Sengupta, S.; Pungrassami, P.; Balthip, Q.; Choonuan, S.; Kasetjaroen, Y.; Strauss, R.P.; Chongsuvivatwong, V. Measuring stigma associated with tuberculosis and HIV/AIDS in southern Thailand: Exploratory and confirmatory factor analyses of two new scales. Trop. Med. Int. Health 2008, 13, 21-30. [CrossRef]

24. Van Brakel, W.H. Measuring health-related stigma-A literature review. Psychol. Health Med. 2006, 11, 307-334. [CrossRef] [PubMed]

25. Freitas, I.M.; Popolin, M.P.; Touso, M.M.; Yamamura, M.; Rodrigues LB, B.; Neto, M.S.; Crispim, J.A.; Arcêncio, R.A. Factors associated with knowledge about tuberculosis and attitudes of relatives of patients with the disease in Ribeirão Preto, São Paulo, Brazil. Revista Brasileira de Epidemiologia 2015, 18, 326-340. [CrossRef] [PubMed]

26. Tolossa, D.; Medhin, G.; Legesse, M. Community knowledge, attitude and practices towards tuberculosis in Shinile town, Somali regional state, eastern Ethiopia: A cross-sectional study. BMC Public Health 2014, 14, 804. [CrossRef] [PubMed]

27. Khan, J.A.; Irfan, M.; Zaki, A.; Beg, M.; Rizvi, N. Knowledge, attitude and misconception regarding tuberculosis in Pakistani Patients. J. Pak. Med. Assoc. 2006, 56, 211-214. [PubMed]

28. Viney, K.A.; Johnson, P.; Tagaro, M.; Fanai, S.; Linh, N.N.; Kelly, P.; Harley, D.; Sleigh, A. Tuberculosis patients' knowledge and beliefs about tuberculosis: A mixed methods study from the Pacific Island nation of Vanuatu. BMC Public Health 2014, 14, 467. [CrossRef] [PubMed]

29. Getahun, H.; Aragaw, D. Tuberculosis in rural northwest Ethiopia: Community perspective. Ethiop. Med. J. 2001, 39, 283-291. [PubMed]

30. Singh, M.M.; Bano, T.; Pagare, D.; Sharma, N.; Devi, R.; Mehra, M. Knowledge and attitude towards tuberculosis in a slum community of Delhi. J. Commun. Dis. 2002, 34, $203-214$.

31. Sommerland, N.; Wouters, E.; Mitchell, E.M.H.; Ngicho, M.; Redwood, L.; Masquillier, C.; van Hoorn, R.; van den Hof, S.; Van Rie, A. Evidence-based interventions to reduce tuberculosis stigma: A systematic review. Int. J. Tuberc. Lung Dis. 2017, 21, S81-S86. [CrossRef]

32. Balogun, M.; Sekoni, A.; Meloni, S.T.; Odukoya, O.; Onajole, A.; Longe-Peters, O.; Ogunsola, F.; Kanki, P.J. Trained community volunteers improve tuberculosis knowledge and attitudes among adults in a periurban community in Southwest Nigeria. Am. J. Trop. Med. Hyg. 2015, 92, 625-632. [CrossRef]

33. Croft, R.P.; Croft, R.A. Knowledge, attitude and practice regarding leprosy and tuberculosis in Bangladesh. Lepr. Rev. 1999, 70, 34-42. [CrossRef]

34. Demissie, M.; Getahun, H.; Lindtjorn, B. Community tuberculosis care through 'TB clubs' in rural North Ethiopia. Soc. Sci. Med. 2003, 56, 2009-2018. [CrossRef]

35. Smith, M. Stigma. Adv. Psychiatr. Treat. 2002, 8, 317-325. [CrossRef]

36. Creamers, A.L.; de Laat, M.M.; Kapata, N.; Gerrets, R.; Klipstein-Grobusch, K.; Grobusch, M.P. Assessing the consequences of stigma for tuberculosis patients in urban Zambia. PLoS ONE 2015, 10, e0119861. [CrossRef] [PubMed]

37. Yin, X.; Yan, S.; Tong, Y.; Peng, X.; Yang, T.; Lu, Z.; Gong, Y. Status of tuberculosis-related stigma and associated factors: A cross-sectional study in central China. Trop. Med. Int. Health 2018, 23, 199-205. [CrossRef] [PubMed]

38. Arcaya, M.C.; Arcaya, A.L.; Subramanian, S.V. Inequalities in health: Definitions, concepts, and theories. Glob. Health Action 2015, 8, 27106. [CrossRef] [PubMed]

39. Boccia, D.; Hargreaves, J.; De Stavola, B.L.; Fielding, K.; Schaap, A.; Godfrey-Faussett, P.; Ayles, H. The association between household socioeconomic position and prevalent tuberculosis in Zambia: A case-control study. PLoS ONE 2011, 6, e20824. [CrossRef] [PubMed]

40. Krishnan, L.; Akande, T.; Shankar, A.V.; McIntire, K.N.; Gounder, C.R.; Gupta, A.; Yang, W.T. Gender-related barriers and delays in accessing tuberculosis diagnostic and treatment services: A systematic review of qualitative studies. Tuberc. Res. Treat. 2014, 2014, 215059. [CrossRef]

41. Ganapathy, S.; Thomas, B.E.; Jawahar, M.S.; Selvi, K.J.; Sivasubramaniam Weiss, M. Perceptions of gender and tuberculosis in a south Indian urban community. Indian J. Tuberc. 2008, 51, 9-14.

42. Onifade, D.A.; Bayer, A.M.; Montoya, R.; Haro, M.; Alva, J.; Franco, J.; Sosa, R.; Valiente, B.; Valera, E.; Ford, C.M.; et al. Gender-related factors influencing tuberculosis control in shantytowns: A qualitative study. BMC Public Health 2010, 10, 381. [CrossRef] 
43. Atre, S.; Kudale, A.; Morankar, S.; Gosoniu, D.; Weiss, M.G. Gender and community views of stigma and tuberculosis in rural Maharashtra, India. Glob. Public Health 2011, 6, 56-71. [CrossRef]

44. Mason, P.H.; Roy, A.; Spillane, J.; Singh, P. Social, historical and cultural dimensions of tuberculosis. J. Biosoc. Sci. 2016, 48, 206-232. [CrossRef] [PubMed]

45. Mason, P.H.; Degeling, C.; Denholm, J. Sociocultural dimensions of tuberculosis: An overview of key concepts. Int. J. Tuberc. Lung Dis. 2015, 19, 1135-1143. [CrossRef] [PubMed]

46. Abebe, G.; Deribew, A.; Apers, L.; Woldemichael, K.; Shiffa, J.; Testaye, M.; Abdissa, A.; Deribie, F.; Jira, C.; Bezabih, M.; et al. Knowledge, health seeking behavior and perceived stigma towards tuberculosis among tuberculosis suspects in a rural community in Southwest Ethiopia. PLoS ONE 2010, 5, e13339. [CrossRef] [PubMed]

47. Guidroz, K.; Berger, M.T. A Conversation with Founding Scholars of Intersectionality: Kimberle Crenshaw, Nira Yuval-Davis, and Michelle Fine. In The Intersectional Approach: Transforming the Academy Through Race, Class $\mathcal{E}$ Gender; Berger, M.T., Guidroz, K., Eds.; The University of North Carolina Press: Chapel Hill, NC, USA, 2009.

48. Hankivsky, O. Women's health, men's health, and gender and health: Implications of intersectionality. Soc. Sci. Med. 2012, 74, 1712-1720. [CrossRef] [PubMed]

49. World Health Organization. Final Report of the Commission on Social Determinants of Health. Closing the Gap in a Generation: Health Equity through Action on the Social Determinants of Health; World Health Organization: Geneva, Switzerland, 2008.

50. McCall, L. Introduction. In The Intersectional Approach: Transforming the Academy Through Race, Class E Gender; Berger, M.T., Guidroz, K., Eds.; The University of North Carolina Press: Chapel Hill, NC, USA, 2009.

(C) 2019 by the authors. Licensee MDPI, Basel, Switzerland. This article is an open access article distributed under the terms and conditions of the Creative Commons Attribution (CC BY) license (http://creativecommons.org/licenses/by/4.0/). 